J. Dairy Sci. 97:2731-2739

http://dx.doi.org/10.3168/jds.2013-7274

(C) American Dairy Science Association ${ }^{\circledR}, 2014$.

\title{
Dairy cows seek isolation at calving and when ill
}

\author{
K. L. Proudfoot, ${ }^{\star} †$ M. B. Jensen, $\neq$ D. M. Weary, ${ }^{*}$ and M. A. G. von Keyserlingk ${ }^{* 1}$ \\ *Animal Welfare Program, Faculty of Land and Food Systems, University of British Columbia, 2357 Main Mall, Vancouver, British Columbia, \\ V6T 1Z4, Canada \\ †Department of Veterinary Preventive Medicine, College of Veterinary Medicine, The Ohio State University, Columbus 43210 \\ ‡Department of Animal Science, Aarhus University, Blichers Allé 20, PO Box 50, DK-8830 Tjele, Denmark
}

\begin{abstract}
Dairy cows are typically gregarious, but isolate themselves in the hours before calving when kept on pasture. Self-isolation is also a common behavior of ill animals. The objectives of this study were to determine if dairy cows would (1) isolate to calve when housed indoors in an individual maternity pen and (2) continue to isolate when ill after calving. We selected individuals from a pool of 79 multiparous Holstein dairy cows based on inclusion criteria created to address each objective. Cows were moved from a group pen to 1 of 10 adjacent maternity pens. Half of these individual pens were partially covered with plywood, creating a secluded corner as well as a window that provided visual access to the group pen. The other individual pens were uncovered on all sides. For our first objective, we selected 39 cows that were moved into the maternity pens $>8 \mathrm{~h}$ before calving (partially covered: $\mathrm{n}=19$; uncovered: $\mathrm{n}=20$ ). For our second objective, we selected 18 cows housed in the partially covered pens: 9 cows with high rectal temperature after calving and signs of an infectious disease (mastitis, metritis, pneumonia, or some combination), and 9 healthy cows paired with ill cows based on the amount of time they spent in the maternity pen before calving. Ten-minute scan sampling was used to record the location and lying time from $6 \mathrm{~h}$ before to $72 \mathrm{~h}$ after calving. Individual feed intake was measured after calving. Binomial tests were used to determine if cows in both pen types were more likely to calve in the corner or window side of the pen. Repeated-measures ANOVA were used to determine if cows used the corner more as calving approached and if ill cows spent more time lying or more time in the corner compared with healthy cows in the $72 \mathrm{~h}$ after calving. Cows in the uncovered pens were equally likely to calve on both sides of the pen (10 vs. 10), but $79 \%$ of cows in the partially covered pens calved on the corner side of the pen (15 vs. 4). Cows in the partially covered pens used
\end{abstract}

Received July 21, 2013.

Accepted January 22, 2014.

${ }^{1}$ Corresponding author: nina@mail.ubc.ca the corner side of the pen more in the $1 \mathrm{~h}$ before and after calving compared with those housed in the uncovered pens. Ill cows housed in the partially covered pens ate less, tended to spend more time lying down, and spent more time in the corner of the pen compared with healthy cows. These results indicate that periparturient dairy cows seek seclusion to calve and when ill, which suggests that adding a secluded area to maternity and hospital pens may be beneficial.

Key words: transition, sickness behavior, parturition

\section{INTRODUCTION}

As herd animals, dairy cows typically synchronize their behaviors and rarely stray from the protection of the group (Miller and Wood-Gush, 1991). However, this behavior can change as the time of calving approaches. Domesticated cows kept on pasture often leave the herd to calve (Lidfors et al., 1994), and at least some wild ungulates (e.g., bison: Lott and Galland, 1985; elk: Barbknecht et al., 2011) show similar self-isolation behavior.

Self-isolation in cattle may not be unique to parturition. In laboratory rodents, isolation is a common sign of illness (Crestani et al., 1991; Arakawa et al., 2010). Dairy cows are at high risk of disease after calving (Ingvartsen, 2006) and behavior is becoming increasingly recognized as useful for identifying ill animals (reviewed by Weary et al., 2009). Recent studies have determined that feeding and standing behaviors can identify cows at risk for postpartum disease (reviewed by SepúlvedaVaras et al., 2013). To our knowledge, no research has determined whether cows will isolate themselves when ill.

On many commercial dairy farms cows are given little opportunity to isolate when calving or when ill. Management and housing of cows at calving and during illness is highly variable; cows are typically either housed in group pens or individual maternity or hospital pens (e.g., Fogsgaard et al., 2012a). Individual pens are often in high-traffic areas, allowing producers easy access to monitor ill and calving cows. In the current study, we modified an individual pen to allow cows 


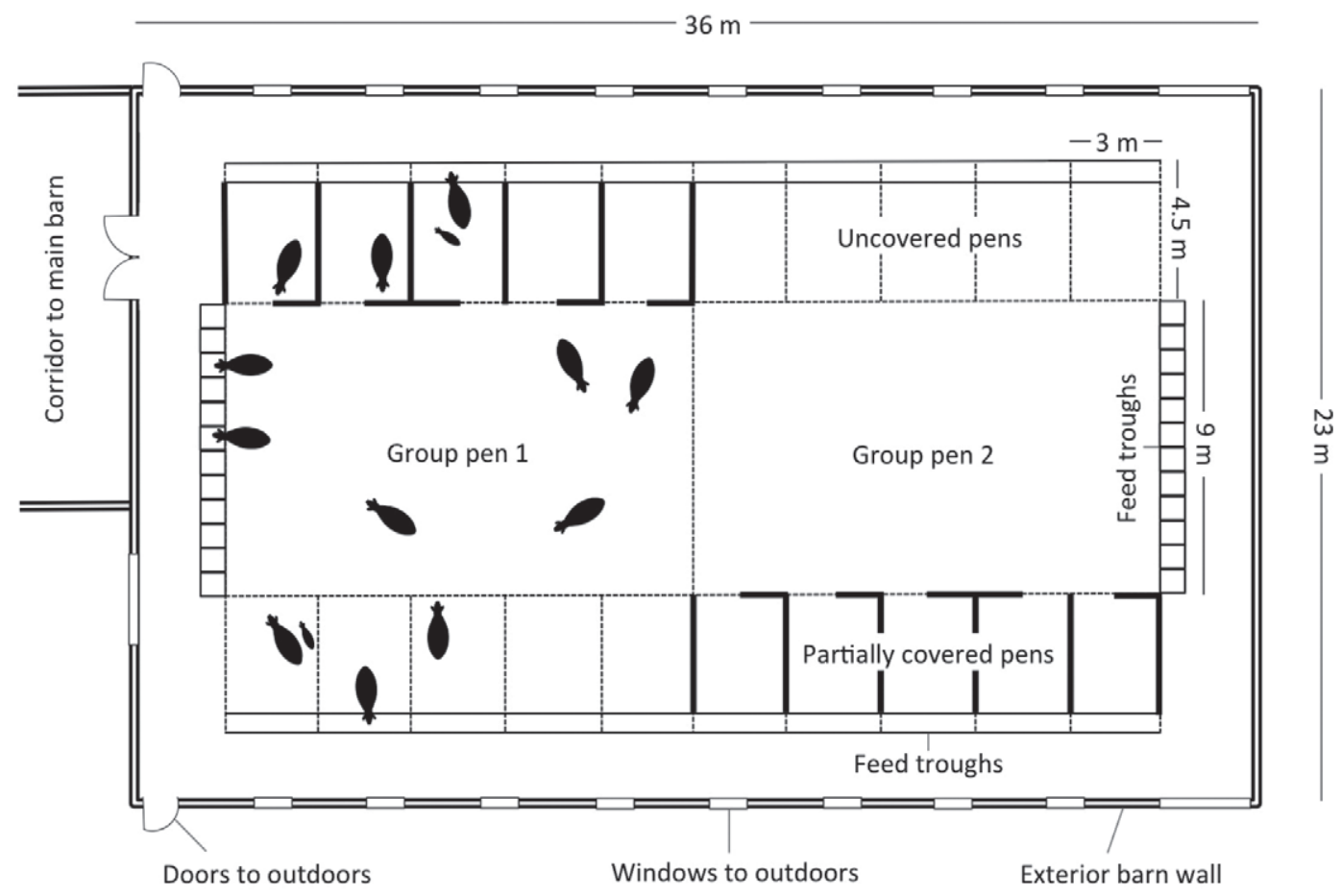

Figure 1. Floor plan of the experimental area. Dashed lines represent tubular metal bars separating group and individual pens, and thick black lines around pens represent plywood used for the partially covered pens.

some visual isolation from herd mates during calving and the first few days after calving. Our objectives were to determine if (1) cows were more likely to calve in a secluded area and (2) cows that became ill after calving would spend more time in the secluded area.

\section{MATERIALS AND METHODS}

The experiment took place at the Aarhus University cattle research facility (Foulum, Denmark) between September 2011 and February 2012. Cows were cared for according to a protocol approved by the Danish Animal Experiments Inspectorate, Ministry of Justice (Copenhagen, Denmark) and the University of British Columbia Animal Care Committee (Vancouver, BC, Canada; CCAC, 2009).

\section{Animals and Housing}

The experiment began with 79 multiparous Danish Holstein dairy cows. Before calving, cows were grouped based on expected calving date into 6 blocks with a mean of 14.7 cows each $(\mathrm{SD}=1.5 ;$ minimum $=12$, maximum $=16)$. The entire block was moved into 1 of 2 group pens (each $9 \times 15 \mathrm{~m}$; Figure 1 ) approximately 2 wk before the first expected calving date of cows within that block. Group pens had deep straw bedding and 12 individual feeding bins (each $75 \mathrm{~cm}$ wide).
Individual cows were moved into maternity pens either before or during signs of labor. Cows were alternately moved into uncovered and partially covered pens, starting with the pen nearest to the feeding troughs. The time at which cows were moved into the individual pen was based upon treatments assigned to them to address a separate research question: the effect of time of movement into the individual pen on labor progress and behavior (see Proudfoot et al., 2013 for a description). To ensure that these treatments did not affect our results, we considered the variation in time that cows spent in the individual pen for both hypotheses tested in this experiment.

The size of each group decreased as cows were moved into maternity pens. Each block consisted of experimental cows as well as nonexperimental cows or heifers with expected calving dates later than the experimental cows. No cows were added to each block, but we ensured that at least 1 nonexperimental cow was in the group pen while the last experimental cow was in the maternity pen.

Figure 2 shows the design of the individual pens. All individual pens were surrounded by $1.3 \mathrm{~m}$-high tubular metal bars on 3 sides and a feed bunk on the fourth side. In half of the pens, a 1.8-m-high plywood barrier fully covered 2 pen sides, and the side facing the group pen was half covered to create one secluded corner and one 1.5-m-wide window that allowed visual contact 
with the group (partially covered). Each individual pen had a door that opened into the group pen so that cows could easily be moved between them. The side of the corner was always the side without the door, as the plywood would have obstructed door movement. For each group pen, 8 pens had the corner on the right side and 2 had the corner on the left side. To account for any side bias in the location of cows within the pen (i.e., one of our main measurements), we created an equal number of uncovered individual pens to act as controls. These pens were exposed on all sides, allowing visual and head-to-head contact with the cows of the same block in the group pen and adjacent individual pens. Cows and their calves remained in the individual pens for $3 \mathrm{~d}$ after calving.

Cows were fed a TMR ad libitum with a forage-toconcentrate ratio of 79:21 (\%, DM basis) before calving and 60:40 (\%, DM basis) after calving. Feed was allocated twice daily at 1000 and $1700 \mathrm{~h}$. After calving, cows were milked twice daily at 0600 and $1800 \mathrm{~h}$ using a manual milking machine. Water was available ad libitum in the group and maternity pens via water bowls.

\section{Inclusion and Exclusion Criteria}

Inclusion criteria for each objective were defined separately. For both objectives, cows were excluded from the experiment if they had calved in the group pen (n $=10)$, experienced a difficult calving or had twins $(\mathrm{n}=$ 7), were disturbed by human activity during labor (i.e., straw added to her pen; $\mathrm{n}=1$ ), or had milk fever on the day of calving $(\mathrm{n}=2)$. Of the 59 remaining cows, 34 were in the partially covered pens and 25 were in the uncovered pens.
Location Before and at Calving. To minimize the effects of novelty, we excluded cows that calved within $8 \mathrm{~h}$ of being moved from the group into the individual pen $(\mathrm{n}=18)$. Two cows were also excluded because they were housed in an uncovered pen with a plywood barrier on one side (both calved next to the barrier). Thus, the final number of cows included to address this research question was 39 (partially covered: $\mathrm{n}=19$; uncovered: $\mathrm{n}=20$ ).

Location and Health Status Postpartum. To determine the effect of illness on the use of the corner side of the pen, we included all cows that were housed in the partially covered pens $(\mathrm{n}=34)$. Some of these cows were also included in the first objective (ill: $\mathrm{n}=$ 5 ; healthy: $\mathrm{n}=5$ ).

To determine health status, rectal body temperature was taken twice daily at milking for the first $3 \mathrm{~d}$ after calving. A health examination was performed 3 and $9 \mathrm{~d}$ after calving by an experienced researcher and technician, or as needed by the herd veterinarian. Cows were checked for signs of metritis using a vaginal exam and a 4-point scoring system (see Huzzey et al., 2007 for a description of this scoring system), and signs of ketosis using a small blood sample from the tail vein [Precision Xtra Ketone Glucose and Ketone Monitoring System (Abbott Laboratories, Abbott Park, IL), validated by Iwersen et al., 2009]. Signs of mastitis were recorded by the milker daily based on the color and consistency of the milk.

Cows were considered ill if they had at least 2 consecutive body temperatures $>39.0^{\circ} \mathrm{C}$ and showed signs of metritis $(\mathrm{n}=2$; a score of 2 or higher, all diagnosed on d 3 after calving), mastitis ( $\mathrm{n}=5 ; 3$ diagnosed on $\mathrm{d} 2$ after calving and 2 diagnosed on $\mathrm{d} 3$ after calving), pneu-
A

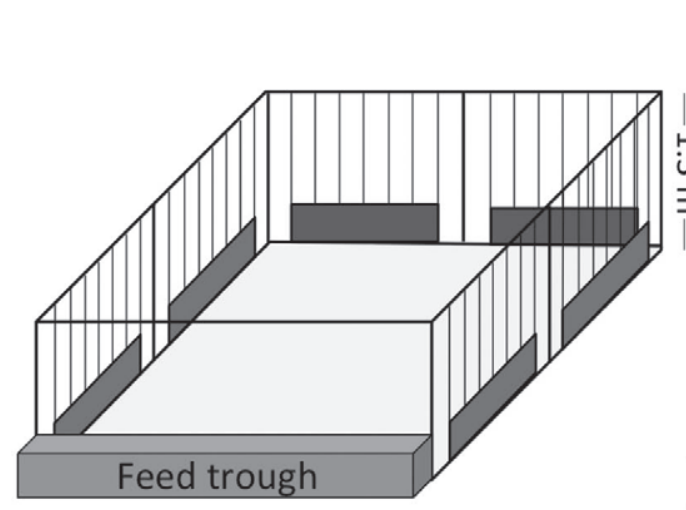

B

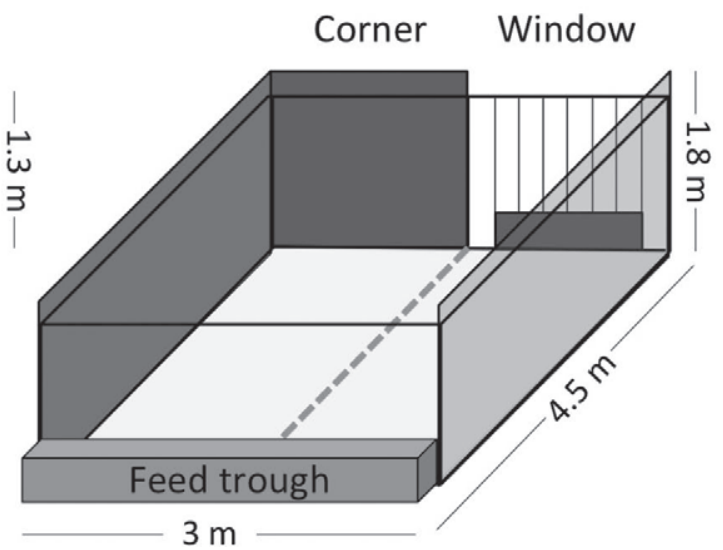

Figure 2. Design of (A) uncovered and (B) partially covered individual maternity pens. Gray squares indicate plywood barriers and black lines indicate tubular metal bars separating pens. Pens were separated into a corner or window half to assign cow location. The side of the corner for each uncovered pen was determined by matching these to partially covered pens. 
monia ( $\mathrm{n}=1$; diagnosed by a veterinarian on $\mathrm{d} 2$ after calving), or a combination of mastitis and metritis (n $=1$; diagnosed on $\mathrm{d} 2$ and 3 after calving, respectively). Cows with mastitis or pneumonia were treated on the day of diagnosis with an injectable antibiotic given by the herd veterinarian according to standard veterinary procedures [pneumonia: Alamycin $300 \mathrm{mg} / \mathrm{mL}, 100 \mathrm{~mL}$ dosage (Norbrook Laboratories Ltd., Corby, UK); mastitis: 1 of the following 3 treatments: penicillin, $100 \mathrm{~mL}$ dosage (Penovet; Boehringer Ingelheim Pharma GmbH \& Co. KG, Ingelheim, Germany); amoxicillin, $150 \mathrm{~mL}$ dosage $(150 \mathrm{mg} / \mathrm{mL}$ Curamox; Boehringer Ingelheim Denmark A/S, Copenhagen, Denmark); or sulfadiazine $200 \mathrm{mg}$ and trimethoprim $40 \mathrm{mg}, 150 \mathrm{~mL}$ dosage (Norodine 24\%; Norbrook Laboratories Ltd.)]. Treatments were repeated by farm staff for $3 \mathrm{~d}$ after diagnosis. The cow with pneumonia and 4 cows with mastitis were also given a nonsteroidal antiinflammatory drug (NSAID) on the day after diagnosis [either flunixin meglumine, $50 \mathrm{mg} / \mathrm{mL}, 20 \mathrm{~mL}$ dosage (Finadyne Solution; MSD Animal Health, Milton Keynes, UK) or Metacam, 20 $\mathrm{mg} / \mathrm{mL}$ solution, $15 \mathrm{~mL}$ dosage (Boehringer Ingelheim Pharma GmbH \& Co. KG)].

Considerable variation existed in the time the 9 ill cows were kept in the maternity pen before calving $($ minimum $=0.8 \mathrm{~h}$, maximum $=120 \mathrm{~h})$. To determine if time in the maternity pen affected behavior after calving, we ran a preliminary regression between time in the maternity pen and time spent in the corner after calving. A negative relationship was detected, whereby cows that spent more time in maternity pen before calving used the corner less $\left(\mathrm{R}^{2}=0.13\right.$; slope $=-2.4$; $P=0.04)$. To avoid any bias in our final analysis, we paired the 9 ill cows with 9 healthy cows (i.e., no clinical signs of infectious or metabolic disease up to $9 \mathrm{~d}$ after calving) by time spent in the maternity pen before calving and included pair in the model.

\section{Behavioral Data Collection}

Behaviors were monitored using digital video cameras (TVCCD-140IR; Monacor UK Ltd., Milton Keynes, UK) mounted above each pen. One experienced observer collected all data from video. The video was used to determine the time and location of the cow at the moment of calving (i.e., when the calf's hips were fully expelled from the dam). Behavior was measured from $6 \mathrm{~h}$ before to $72 \mathrm{~h}$ after calving using 10-min scan sampling. During each scan, the location of the cow in the pen, the posture of the cow (standing or lying), and the proximity of the calf and the cow (i.e., within or greater than 1 calf-length apart) were recorded.

Figure 2 shows the 2 options for cow location: (1) the corner where the plywood barrier prevented visual and physical contact to the cows housed in the group pen and (2) the window where cows could have visual and head-to-head contact with the cows in the group pen. A cow was considered to be in the corner or window when the majority of her body was contained within the area. In the few exceptions where she was positioned directly in the center of the pen and it was difficult to distinguish which side of the pen she was on, we recorded this as center [cows spent $11.0 \pm 7.8$ (mean $\pm \mathrm{SD}) \mathrm{min} / \mathrm{h}$ in the center of the pen]. If a cow was categorized in the center of the pen at the moment of calving, we measured how much of their body was on each side of the pen and reassigned her to be in either the corner or window side (partially covered: $\mathrm{n}=1$; uncovered: $\mathrm{n}$ $=3$ ). We matched each partially covered pen with an uncovered pen to determine the side of the window and corner for the uncovered pens.

For ill and healthy cows, feed intake was measured before morning delivery at $1000 \mathrm{~h}$ and any feed refusals were weighed and removed the next morning before fresh feed was delivered. Daily feed intake (on a \% DM basis) was calculated as the difference between feed delivery and feed refusals. If a cow calved before fresh feed delivery at $1000 \mathrm{~h}$, DMI on the day of calving and the 2 following days were included in the analysis (healthy: $\mathrm{n}=4$; ill: $\mathrm{n}=5$ ). If cows calved after fresh feed delivery, DMI on the day after calving and the 2 following days were included in the analysis (healthy: $\mathrm{n}$ $=5$; ill: $\mathrm{n}=4$ ).

\section{Statistical Analysis}

All statistical analyses were performed with SAS software (version 9.2; SAS Institute Inc., Cary, NC) using the cow as the experimental unit. To test if the number of cows in the pen affected behavioral responses, our preliminary analysis including the number of cows in the group pen as a covariate; no effect of this variable was observed on any measure, so this variable will not be discussed further. Two-tailed binomial tests were used to determine if cows were more likely to calve on one side or the other when housed in the partially covered or uncovered pens (with a reference of $50 \%$ ).

To determine if cows changed their use of the corner in the hours around calving, video data were summed by hour for the $6 \mathrm{~h}$ before calving until the $4 \mathrm{~h}$ after calving. Data were analyzed with repeated-measures ANOVA (PROC MIXED); the model included pen type (uncovered or covered), hour, and a pen type $\times$ hour interaction. Cow was included as a random effect and the correlation between repeated hourly measures was modeled with compound symmetry. After visual inspection of the graph, specific contrasts were made between treatments in the $1 \mathrm{~h}$ before and $1 \mathrm{~h}$ after calv- 
ing using the ESTIMATE statement of PROC MIXED. For calf location, data after calving were analyzed using repeated-measures ANOVA (PROC MIXED); the model included pen type (uncovered or covered), hour, and a pen type $\times$ hour interaction. The correlation between repeated hourly measures was modeled with compound symmetry and the cow-calf pair was considered the random effect. We observed a clear linear reduction in time that cows and calves spent near each other over the $4 \mathrm{~h}$ after calving, so hour was modeled as a continuous variable to determine the rate of change (slope).

To determine if ill cows spent more time lying and more time in the corner during the $72 \mathrm{~h}$ after calving compared with healthy cows, data were first summed per 24 -h period $(0$ to $23 \mathrm{~h}=24 \mathrm{~h}, 24$ to $47 \mathrm{~h}=48 \mathrm{~h}$, and 48 to $71 \mathrm{~h}=72 \mathrm{~h}$ ). Video data were missing for 1 ill cow during the 48- and 72-h periods and for 1 ill cow during the 72-h period after calving. Data were analyzed with repeated-measures ANOVA (PROC MIXED); the model included pair, health (ill or healthy), 24-h period, and a health $\times$ period interaction. Cow was included as a random effect, and the correlation between repeated hourly measurements was modeled with autoregressive covariance. For calf location, data after calving were analyzed using repeated-measures ANOVA (PROC MIXED); the model included pair, health (ill or healthy), 24-h period, and a health $\times$ period interaction. The correlation between repeated hourly measures was modeled with compound symmetry and the cow-calf pair was considered the random effect. Specific contrasts were made between the first 24-h period versus the subsequent 2 periods (48 and $72 \mathrm{~h}$ ).

To determine if ill cows ate less than healthy cows in the first $3 \mathrm{~d}$ after calving, data were analyzed with repeated-measures ANOVA (PROC MIXED). These $3 \mathrm{~d}$ differed from the $72 \mathrm{~h}$ after calving used above, as day here represents a 24 -h clock, whereas the $24-\mathrm{h}$ periods after calving were based on actual calving time. The model included pair, health (ill or healthy), day, period $\times$ health interaction, and cow as a random effect. After visual inspection of the graph and a period $\times$ health interaction $(P=0.01)$, specific contrasts were made between health categories using the ESTIMATE statement of PROC MIXED.

\section{RESULTS}

\section{Location of Cows at Calving}

Figure 3 shows the calving location of cows housed in uncovered and partially covered pens. Cows in the uncovered pen showed no side preference; 10 calved on the corner side and the other 10 calved on the window

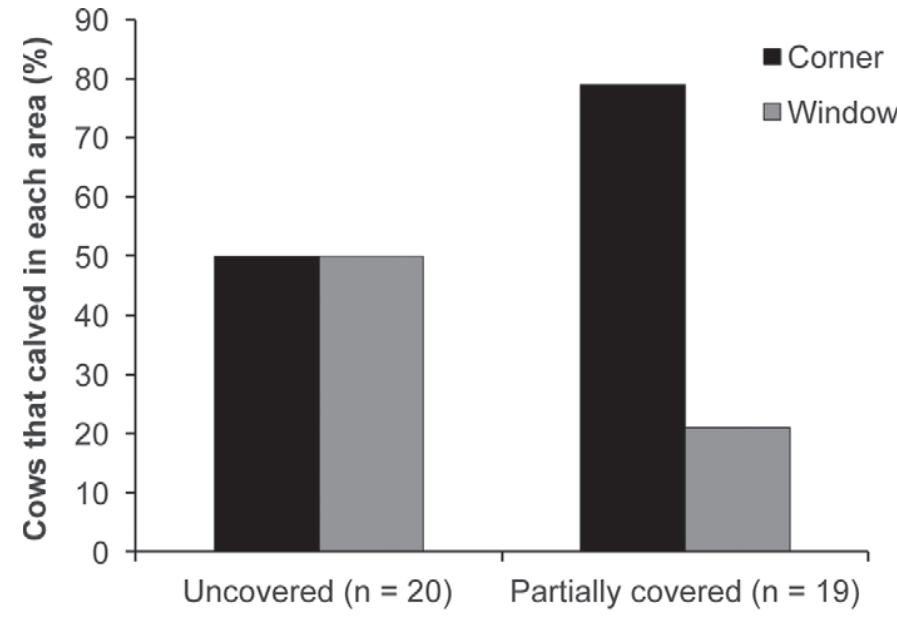

Pen type

Figure 3. Percentage of cows that calved in the corner and window sides of partially covered $(\mathrm{n}=19)$ and uncovered $(\mathrm{n}=20)$ individual maternity pens.

side of the pen. Cows housed in the partially covered pens preferred to calve in the corner, with 15 of 19 cows calving on this side $(P=0.01)$.

\section{Location of Cow and Calf Around Calving}

A pen type $\times$ hour interaction was detected for the time spent in the corner (Figure $4 ; P=0.04$ ). Cows housed in the partially covered pen used the corner more in the $1 \mathrm{~h}$ before $(-1 \mathrm{~h} ; P=0.003)$ and $1 \mathrm{~h}$ after $(0 \mathrm{~h} ; P=0.02)$ calving compared with those housed in the uncovered pens.

No effect of pen type on calf location existed, but a linear reduction was observed in the time that calves spent within one-calf length of the cow over the $4 \mathrm{~h}$ after calving (Slope $=-4.2, P<0.01$ ). Calves were near the cow for almost the full hour in the first hour after calving $(56.4 \pm 1.8 \mathrm{~min} / \mathrm{h})$, and this was reduced to $43.6 \pm 1.8 \mathrm{~min} / \mathrm{h}$ by $4 \mathrm{~h}$ after calving.

\section{DMI, Location of III and Healthy Cows, and Location of Calves After Calving}

For DMI, a day $\times$ health interaction $(P=0.02)$ was detected; ill cows ate less than healthy cows on the first day after calving (13.4 vs. $20.4 \pm 1.1 \mathrm{~kg}$ of DM/d; $P<$ $0.001)$, but not on d 2 (18.5 vs. $20.1 \pm 1.1 \mathrm{~kg}$ of DM/d; $P=0.32)$ or $\mathrm{d} 3(19.5$ vs. $19.6 \pm 1.2 \mathrm{~kg}$ of $\mathrm{DM} / \mathrm{d} ; P$ $=0.95)$.

Figure 5 shows the lying time and time spent in the corner for ill and healthy cows. Ill cows tended to spend more time lying $(P=0.08)$ and spent more time in the corner compared with healthy cows during the $3 \mathrm{~d}$ after 


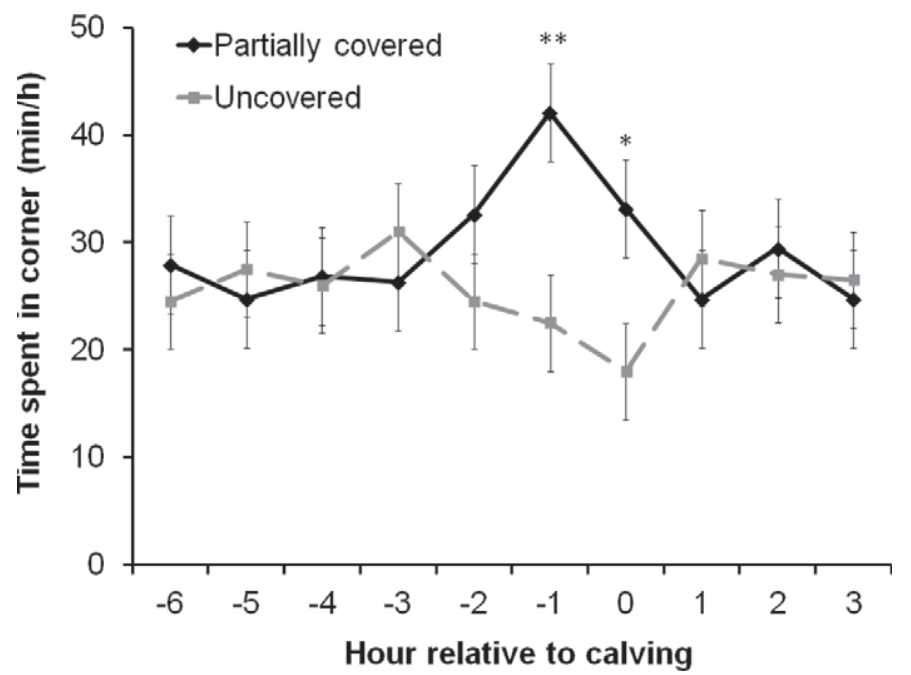

Figure 4. Least squares means $\pm \mathrm{SE}$ of time spent in the corner side of the pen from $6 \mathrm{~h}$ before calving until $4 \mathrm{~h}$ after calving $(0 \mathrm{~h}$ refers to the first hour after calving) for cows housed in partially covered (n $=19)$ and uncovered $(\mathrm{n}=20)$ individual maternity pens $(\mathrm{min} / \mathrm{h}) .{ }^{*} P$ $<0.05 ; * * P<0.01$.

calving $(P<0.001)$. No interactions between period and health were detected for lying time or time spent in the corner.

No effect of illness on calf location was observed, but cows and calves spent the most time near each other in the first $24 \mathrm{~h}$ after calving compared with the next 2 periods $(24 \mathrm{~h}: 16.0 \pm 0.6 \mathrm{~h} / 24 \mathrm{~h} ; 48 \mathrm{~h}: 12.0 \pm 0.7 \mathrm{~h} / 24$ h; 72 h: $12.3 \pm 0.7$ h/24 h; 24 vs. 48 h: $P<0.0001 ; 24$ vs. 72 h: $P<0.001)$.

\section{DISCUSSION}

The objectives of this study were to determine if cows sought seclusion during calving and illness. We provided cows a pen that allowed them to spend time in a secluded area or an open area with visual access and head-to-head contact with cows in a group pen. Cows preferred to use a secluded area for calving and began to use this area more in the $1 \mathrm{~h}$ before calving. After calving, cows that became ill continued to use the secluded area more than healthy cows.

Our finding that cows used a secluded area to calve agrees with an earlier study using domesticated cows kept on pasture (Lidfors et al., 1994) and a study using indoor-housed cows (Proudfoot et al., 2014). On pasture, cows distanced themselves from the herd on the day of calving, choosing to calve in a dry area surrounded by tree or bush cover (Lidfors et al., 1994). Similar to other "hider" species, calves spent the first few days of life hidden in brush or tree cover in a similar location to where they were born while the dam grazed nearby (Vitale et al., 1986). If no suitable cover was available, cows calved within close proximity of the herd (Lidfors et al., 1994). When housed indoors, cows sought the seclusion of a large shelter at calving if they calved in the daytime (Proudfoot et al., 2014), but not if they calved at night.

Cows in the current study secluded themselves for a short time period around calving ( $1 \mathrm{~h}$ before to $1 \mathrm{~h}$ after). In other studies, cows were reported to begin to isolate much earlier, including 24 and $8 \mathrm{~h}$ before calving (Lidfors et al., 1994; Proudfoot et al., 2014, respectively). The difference between our results and those of previous studies could be partially due to sampling technique. Lidfors et al. (1994) averaged data over 24-h periods, limiting the sensitivity to detect when the behavior started. However, Proudfoot et al. (2014) recorded behavior hourly using the same method as in the current study. The difference between studies may also be due to the size of the secluded area in the maternity pen. As cows approach calving, they become

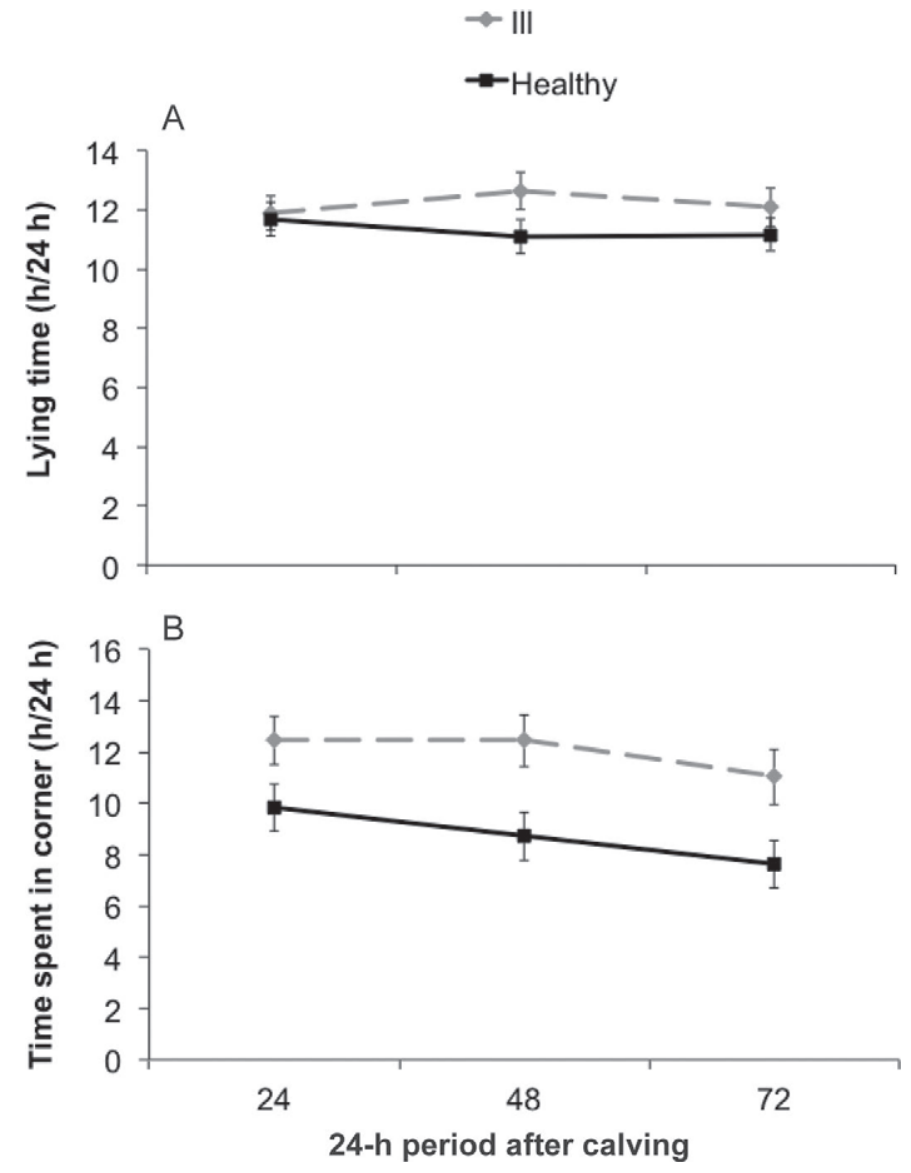

Figure 5. Least squares means $\pm \mathrm{SE}$ for (A) lying time and (B) time spent in the corner for ill $(\mathrm{n}=9)$ and healthy $(\mathrm{n}=9)$ cows housed in the partially covered pens during the $72 \mathrm{~h}$ after calving (h/24-h period). 
restless, characterized by increased postural transitions from standing to lying (Huzzey et al., 2005; Jensen, $2012)$. The small size of our pens $(4.5 \times 3 \mathrm{~m})$ did not allow us to determine if a cow was switching sides of the pen or was simply restless, as cows changed their location within the pen (from the corner to the window side and vice versa) when they transitioned between lying and standing. Cows increased their use of the secluded area in the hour before calving when restlessness is known to be high, suggesting that the motivation to hide may have increased as calving became imminent.

Cows in the partially covered pens also spent more time in the secluded area in the hour after calving. This behavior is likely due to the position of the calf at calving, as most cows in the partially covered pens calved in the secluded area, and regardless of pen type, cows spent most of this hour near the calf. Cows spend the first few hours after calving licking the calf (Edwards and Broom, 1982; Jensen, 2012); licking is thought to be essential for the development of the dam-calf bond (Hudson and Mullord, 1977). Our results showed that cows spent a relatively short time in seclusion after calving. This could be due to the small size of the pen and potential soiling in the secluded corner due to calving, or could suggest that the cow is ready to re-enter the herd soon after calving.

For our second research question, we hypothesized that cows would also seek seclusion as a result of illness. When an animal becomes ill with an infectious disease, 2 key changes occur to help the animal fight the infection: (1) a febrile (fever) response and (2) strategic behavioral changes that conserve and redirect energy to the immune system (Hart, 1988). Sickness behaviors are driven by signals from the immune system in the brain (e.g., cytokines such as IL-1; Kelley et al., 2003), are generally nonspecific, and include a reduction in feed intake and feeding behavior as well as a general reduction in activity and social behaviors (Dantzer, 2001).

Cows with signs of infectious disease and a febrile response ate less than healthy cows on the first day after calving. A similar response has been found in other studies using cows with metritis (Huzzey et al., 2007) and mastitis (Fogsgaard et al., 2012b) in early lactation. This difference disappeared in the following $2 \mathrm{~d}$, likely because 7 of the 9 ill cows were treated for their illnesses ( 5 on d 2 and 2 on d 3 ). Ill cows also tended to spend more time lying down, also a common sickness behavior. However, this result differs from that in previous work, which showed that mastitic cows spent less time lying compared with healthy cows as a means to avoid pressure and pain from the udder (Siivonen et al., 2011; Cyples et al., 2012; Fogsgaard et al., 2012b). Cows with metritis and pneumonia likely accounted for the tendency for higher lying time of ill animals reported here.

A novel finding from the current study was that ill cows spent more time in the secluded area compared with healthy cows. Although this is the first evidence for isolation behavior in ill dairy cows, reduced social exploration has been found in studies of sickness behavior in laboratory animals (e.g., Crestani et al., 1991; Bluthé et al., 1999). In those studies, sickness behavior was caused by injecting the animals with either LPS (an endotoxin) or IL-1 to mimic an infectious disease. Animals infected with LPS or IL-1 reduced social exploration when presented with a conspecific (e.g., sniffing, grooming, and chasing; Crestani et al., 1991; Bluthé et al., 1999). In addition to reduced social exploration, evidence also exists that mice reduce maternal behaviors when ill (Aubert et al., 1997). We did not find any effects of illness on the time that the cow and calf spent near each other, but did not specifically measure maternal behavior. Further studies are encouraged to determine the effects of illness on maternal behaviors in cattle, such as allowing the calf to nurse or initiating contact with the calf. One limitation of the current study was the small number of ill cows affected with 3 different diseases. Although sickness behaviors are normally generalized across infectious diseases when a fever is present (Hart, 1988), it would be useful to conduct a larger study to reduce some of the variation due to illness type and severity as well as day of diagnosis and treatment.

The reasons for isolation during calving and illness remain unknown. In wild ungulates, it is thought that cows hide during calving as an anti-predator strategy or to facilitate the dam-calf bond by preventing disturbance from other cows (Leuthold, 1977). In our case, the partially covered maternity pen allowed cows to isolate from the adjacent group pen of familiar cows (as they had been housed with them before calving), while allowing some head-to-head contact via the window. Before calving, cows may have been using the secluded area to avoid attention from cows in the group pen drawn to odors associated with calving (see Proudfoot et al., 2013 for an example of this behavior). It is unclear how behavior may have been affected by the presence of unfamiliar cows (as would be the case for heifers introduced to the lactating herd for the first time). Ill animals may also benefit from avoiding others, in part to reduce the risk of secondary infection (Loehle, 1995). However, evidence also exists that support from social partners may have health benefits (reviewed by Rault, 2012).

Cows may also hide to avoid noise and activity in the barn. In our previous study (Proudfoot et al., 2014), indoor-housed cows used a shelter to calve during the 
daytime; we speculated that this behavior may have been partly driven by the high traffic of people and cows in the barn during that time, as the study was conducted on a busy research farm. A wide range in the activity around maternity and hospital pens in commercial herds likely exists, as this is influenced by farm size and location of the pens relative to high-activity areas such as the milking parlor. In the present study, we did not have a large enough sample of cows that calved on each side of the partially covered pen to assess how time of day influenced the cows' choice, but the 4 cows that calved in the window side did so during the daytime. It should also be noted that human activity in the barn was minimal; activity was limited to feeding and milking, or when cows were inspected for signs of labor.

Cows may use a secluded area to be protected from drafts in the barn. Although no evidence exists that cows seek warmth during calving, evidence exists that wild ungulates will seek warm areas when ill (Hetem et al., 2008) and Holstein steers housed outdoors will increase use of a shelter when ill (White et al., 2012). In our case, the barn was naturally ventilated with windows, and the maternity pens were situated against walls with windows so any air coming into the barn would move through the maternity pens. However, the plywood barrier may have created a favorable microclimate in the secluded corner.

These ideas are not mutually exclusive; a combination of factors likely influences the decision to seek a secluded area around calving and during illness. Further research is encouraged to determine the mechanisms that motivate isolation seeking. The mechanisms of sickness behavior are becoming relatively well known, including the role of proinflammatory cytokines (Dantzer, 2001). Similar mechanisms may contribute to seclusion at calving (e.g., Sordillo et al., 1995), but this remains unknown.

\section{CONCLUSIONS}

When given the opportunity, cows housed in individual maternity pens preferentially used a secluded area to calve. Cows began using the secluded area more in the hour before calving and continued to use it more for the hour after calving. Ill cows ate less, tended to spend more time lying, and spent more time using the secluded area compared with healthy cows.

\section{ACKNOWLEDGMENTS}

We gratefully acknowledge the barn staff of the cattle facility at Aarhus University Research Centre Foulum (Tjele, Denmark). We also thank John Misa Obidah and Erik Luc Decker of Aarhus University for their help with data collection and handling. K. L. Proudfoot was funded in part by The Aarhus University Research Foundation as a visiting PhD student and a Natural Sciences and Engineering Research Council of Canada (NSERC, Ottawa, ON, Canada) Discovery Grant awarded to M. A. G. von Keyserlingk. The research was funded by the Danish Ministry of Food, Agriculture and Fisheries (Copenhagen, Denmark).

\section{REFERENCES}

Arakawa, H., K. Arakawa, and T. Deak. 2010. Sickness-related odor communication signals as determinants of social behavior in rat: A role for inflammatory processes. Horm. Behav. 57:330-341.

Aubert, A., G. Goodall, R. Dantzer, and G. Gheusi. 1997. Differential effects of lipopolysaccharide on pup retrieving and nest building in lactating mice. Brain Behav. Immun. 11:107-118.

Barbknecht, A. E., W. S. Fairbanks, J. D. Rogerson, E. J. Maichak, B. M. Scurlock, and L. L. Meadows. 2011. Elk parturition site selection at local and landscape scales. J. Wildl. Manage. 75:646-654.

Bluthé, R.-M., N. Castanon, F. Pousset, A. Bristow, C. Ball, J. Lestage, B. Michaud, K. W. Kelley, and R. Dantzer. 1999. Central injection of IL-10 antagonizes the behavioural effects of lipopolysaccharide in rats. Psychoneuroendocrinology 24:301-311.

CCAC (Canadian Council on Animal Care). 2009. CCAC Guidelines on: The Care and use of Farm Animals in Research, Teaching and Testing. CCAC, Ottawa, ON, Canada.

Crestani, F., F. Seguy, and R. Dantzer. 1991. Behavioural effects of peripherally injected interleukin-1: Role of prostaglandins. Brain Res. 542:330-335.

Cyples, J. A., C. E. Fitzpatrick, K. E. Leslie, T. J. DeVries, D. B Haley, and N. Chapinal. 2012. Short communication: The effects of experimentally induced Escherichia coli clinical mastitis on lying behavior of dairy cows. J. Dairy Sci. 95:2571-2575.

Dantzer, R. 2001. Cytokine-induced sickness behavior: Where do we stand? Brain Behav. Immun. 15:7-24.

Edwards, S. A., and D. M. Broom. 1982. Behavioural interactions of dairy cows with their newborn calves and the effects of parity. Anim. Behav. 30:525-535.

Fogsgaard, K. K., M. S. Herskin, P. J. Gorden, A. M. O'Connor, L. L. Timms, and S. T. Millman. 2012a. Survey of management and design of hospital pens at Iowa dairy farms. Pages 40-41 in Proc. Dairy Cattle Welf. Symp., Guelph, ON, Canada. Univ. Guelph, Guelph, ON, Canada.

Fogsgaard, K. K., C. M. Røntved, P. Sørensen, and M. S. Herskin. 2012b. Sickness behavior in dairy cows during Escherichia coli mastitis. J. Dairy Sci. 95:630-638.

Hart, B. L. 1988. Biological basis of the behavior of sick animals. Neurosci. Biobehav. Rev. 12:123-137.

Hetem, R. S., D. Mitchell, S. K. Maloney, L. C. R. Meyer, L. G. Fick, G. I. H. Kerley, and A. Fuller. 2008. Fever and sickness behavior during an opportunistic infection in a free-living antelope, the greater kudu (Tragelaphus strepsiceros). Am. J. Physiol. Regul. Integr. Comp. Physiol. 294:R246-R254.

Hudson, S. J., and M. M. Mullord. 1977. Investigations of maternal bonding in dairy cattle. Appl. Anim. Ethol. 3:271-276.

Huzzey, J. M., D. M. Veira, D. M. Weary, and M. A. G. von Keyserlingk. 2007. Prepartum behavior and dry matter intake identify dairy cows at risk for metritis. J. Dairy Sci. 90:3220-3233.

Huzzey, J. M., M. A. G. von Keyserlingk, and D. M. Weary. 2005. Changes in feeding, drinking, and standing behavior of dairy cows during the transition period. J. Dairy Sci. 88:2454-2461.

Ingvartsen, K. L. 2006. Feeding- and management-related diseases in the transition cow: Physiological adaptations around calving and strategies to reduce feeding-related diseases. Anim. Feed Sci. Technol. 126:175-213. 
Iwersen, M., U. Falkenberg, R. Voigtsberger, D. Forderung, and W. Heuwieser. 2009. Evaluation of an electronic cowside test to detect subclinical ketosis in dairy cows. J. Dairy Sci. 92:2618-2624.

Jensen, M. B. 2012. Behaviour around the time of calving in dairy cows. Appl. Anim. Behav. Sci. 139:195-202.

Kelley, K. W., R.-M. Bluthé, R. Dantzer, J.-H. Zhou, W.-H. Shen, R. W. Johnson, and S. R. Broussard. 2003. Cytokine-induced sickness behavior. Brain Behav. Immun. 17(Suppl. 1):S112-S118.

Leuthold, W. 1977. African Ungulates. Springer, Berlin, Germany.

Lidfors, L. M., D. Moran, J. Jung, P. Jensen, and H. Castren. 1994. Behaviour at calving and choice of calving place in cattle kept in different environments. Appl. Anim. Behav. Sci. 42:11-28.

Loehle, C. 1995. Social barriers to pathogen transmission in wild animal populations. Ecology 76:326-335.

Lott, D. F., and J. C. Galland. 1985. Parturition in American bison: Precocity and systematic variation in cow isolation. Z. Tierpsychol. 69:66-71.

Miller, K., and D. G. M. Wood-Gush. 1991. Some effects of housing on the social behaviour of dairy cows. Anim. Prod. 53:271-278.

Proudfoot, K. L., M. B. Jensen, P. M. H. Heegaard, and M. A. G. von Keyserlingk. 2013. Effect of moving dairy cows at different stages of labor on behavior during parturition. J. Dairy Sci. 96:16381646.

Proudfoot, K. L., D. M. Weary, and M. A. G. von Keyserlingk. 2014. Maternal isolation behavior of Holstein dairy cows kept indoors. J. Anim. Sci. 92:277-281.
Rault, J.-L. 2012. Friends with benefits: Social support and its relevance for farm animal welfare. Appl. Anim. Behav. Sci. 136:1-14.

Sepúlveda-Varas, P., J. M. Huzzey, D. M. Weary, and M. A. G. von Keyserlingk. 2013. Behaviour, illness and management during the periparturient period in dairy cows. Anim. Prod. Sci. 53:988-999.

Siivonen, J., S. Taponen, M. Hovinen, M. Pastell, B. J. Lensink, S. Pyörälä, and L. Hänninen. 2011. Impact of acute clinical mastitis on cow behaviour. Appl. Anim. Behav. Sci. 132:101-106.

Sordillo, L. M., G. M. Pighetti, and M. R. Davis. 1995. Enhanced production of bovine tumor necrosis factor- $\alpha$ during the periparturient period. Vet. Immunol. Immunopathol. 49:263-270.

Vitale, A. F., M. Tenucci, M. Papini, and S. Lovari. 1986. Social behaviour of the calves of semi-wild Maremma cattle, Bos primigenius taurus. Appl. Anim. Behav. Sci. 16:217-231.

Weary, D. M., J. M. Huzzey, and M. A. G. von Keyserlingk. 2009 Board-Invited Review: Using behavior to predict and identify ill health in animals. J. Anim. Sci. 87:770-777.

White, B. J., D. E. Anderson, D. G. Renter, R. L. Larson, D. A. Mosier, L. L. Kelly, M. E. Theurer, B. D. Robert, and M. L. Walz. 2012. Clinical, behavioral, and pulmonary changes in calves following inoculation with Mycoplasma bovis. Am. J. Vet. Res. 73:490-497. 